\title{
Gap Junctions in the Ventral Hippocampal-Medial Prefrontal Pathway Are Involved in Anxiety Regulation
}

\author{
Timothy J. Schoenfeld, ${ }^{1}$ Alexander D. Kloth, ${ }^{2}$ Brian Hsueh, ${ }^{1}$ Matthew B. Runkle, ${ }^{1}$ Gary A. Kane, ${ }^{1}$ Samuel S.-H. Wang, ${ }^{2}$ \\ and Elizabeth Gould ${ }^{1}$ \\ Departments of ${ }^{1}$ Psychology and ${ }^{2}$ Molecular Biology and Princeton Neuroscience Institute, Princeton University, Princeton, New Jersey 08544
}

\begin{abstract}
Anxiety disorders are highly prevalent but little is known about their underlying mechanisms. Gap junctions exist in brain regions important for anxiety regulation, such as the ventral hippocampus (vHIP) and $\mathrm{mPFC}$, but their functions in these areas have not been investigated. Using pharmacological blockade of neuronal gap junctions combined with electrophysiological recordings, we found that gap junctions play a role in theta rhythm in the vHIP and mPFC of adult mice. Bilateral infusion of neuronal gap junction blockers into the vHIP decreased anxiety-like behavior on the elevated plus maze and open field. Similar anxiolytic effects were observed with unilateral infusion of these drugs into the vHIP combined with contralateral infusion into the MPFC. No change in anxious behavior was observed with gap junction blockade in the unilateral vHIP alone or in the bilateral dorsal HIP. Since physical exercise is known to reduce anxiety, we examined the effects of long-term running on the expression of the neuronal gap junction protein connexin-36 among inhibitory interneurons and found a reduction in the vHIP. Despite this change, we observed no alteration in theta frequency or power in long-term runners. Collectively, these findings suggest that neuronal gap junctions in the vHIP-mPFC pathway are important for theta rhythm and anxiety regulation under sedentary conditions but that additional mechanisms are likely involved in running-induced reduction in anxiety.
\end{abstract}

Key words: anxiety; connexin; gap junctions; medial prefrontal cortex; theta rhythm; ventral hippocampus

\section{Introduction}

Understanding the neural basis of anxiety regulation is critical for devising more effective therapies for anxiety disorders, the most prevalent of psychiatric illnesses (Kessler et al., 2005). Lesion, inactivation, pharmacological, and electrophysiological studies reveal that the rodent vHIP and $\mathrm{mPFC}$ are important for anxiety regulation (Bannerman et al., 2003; Shah et al., 2004; Adhikari et al., 2010; McEown and Treit, 2010, 2011, 2013). In particular, coincidence of neuronal oscillations in the theta range between vHIP and mPFC correlates with an anxious state (Adhikari et al., 2010), suggesting that theta may act as a neural correlate or even a causal factor in anxiety regulation.

In dorsal hippocampus (dHIP), theta (as elicited by brainstem stimulation in anesthetized rodents) is shifted to lower frequencies by anxiolytic drugs (McNaughton et al., 2007; Yeung et al., 2012, 2013a). However, anxiogenic drugs do not produce frequency increases (Yeung et al., 2013b). dHIP is more often associated with conditioned fear as opposed to anxiety (McEown and

\footnotetext{
Received July 29, 2013; revised Sept. 9, 2014; accepted Sept. 11, 2014.

Author contributions: T.J.S., A.D.K., and E.G. designed research;T.J.S., A.D.K., B.H., M.B.R., and G.A.K. performed research; T.J.S., A.D.K., B.H., G.A.K., and S.S.-H.W. analyzed data; T.J.S., A.D.K., G.A.K., S.S.-H.W., and E.G. wrote the paper.

This work was supported by grants from the National Institute of Mental Health (MH091567 to E.G., NS045193 to

S.S.-H.W., and MH098651 to A.D.K.). We thank Daniel Takahashi for helpful comments on the spectral analysis.

The authors declare no competing financial interests.

Correspondence should be addressed to Elizabeth Gould, Department of Psychology and Princeton Neuroscience Institute, Princeton University, Princeton, NJ 08544. E-mail: goulde@princeton.edu.

DOI:10.1523/JNEUROSCI.3234-13.2014

Copyright $\odot 2014$ the authors $\quad 0270-6474 / 14 / 3415679-10 \$ 15.00 / 0$
}

Treit, 2010, 2011, 2013), with theta linked to learning and memory (Söhl et al., 2005; O'Keefe, 2007; Allen et al., 2011; Bissiere et al., 2011). In contrast to dHIP, vHIP projects to $\mathrm{mPFC}$ and has strong bidirectional connectivity with the amygdala (Fanselow and Dong, 2010). Thus, vHIP represents a potentially important target for further investigation of theta rhythm and anxiety.

Dorsal hippocampal theta rhythm requires neuronal gap junction signaling, since blockade of gap junctions reduces theta power in dHIP (Bissiere et al., 2011). Specifically implicated is gap junction signaling among a subtype of inhibitory interneurons, the parvalbumin-positive basket cells (Klausberger et al., 2003), which are also found in vHIP and mPFC. Transgenic mice lacking the neuronal gap junction protein connexin-36 (cx-36), which is specific to neuron-neuron gap junctions (Connors and Long, 2004; Collignon et al., 2006), show no differences in anxiety-like behavior from wild-type mice (Frisch et al., 2005). However, these animals lack cx-36 globally throughout development, leaving open the possibility of long-term compensatory mechanisms. While studies have associated a lack of astrocytic gap junction signaling with anxiety (Prochnow et al., 2012; Sun et al., 2012; Zlomuzica et al., 2012), no previous work has investigated whether neuronal gap junction signaling in the vHIP and $\mathrm{mPFC}$ contributes to anxiety and whether these effects are associated with changes in theta.

To avoid confounds associated with long-term adaptation, we manipulated gap junctions acutely in wild-type mice using the pharmacological gap junction blockers mefloquine and carbenoxolone. We asked whether blocking gap junctions in vHIP or in the vHIP-mPFC pathway would alter two anxiety measures in adult mice, elevated plus maze (EPM) and open field (OF). In 
addition, since long-term running is anxiolytic (Duman et al., 2008; Schoenfeld et al., 2013), we investigated whether this behavior was associated with changes in theta rhythm as well as in the expression of the neuronal gap junction protein $\mathrm{cx}-36$ in the vHIP and mPFC.

\section{Materials and Methods}

Experimental design. To test whether gap junction inhibition affects anxiety-like behavior, mice were subjected to injection of gap junction inhibitors or the vehicle either peripherally or directly into various brain regions (dHIP, vHIP, and $\mathrm{mPFC}$ ). Separate groups of these mice were tested for anxiety-like behavior on the EPM or the OF. To test whether gap junction inhibition affects theta rhythm in the vHIP and mPFC, additional mice were injected peripherally with gap junction inhibitors or vehicle and electrophysiological recordings were made from the vHIP or $\mathrm{mPFC}$ before and after drug treatment. To verify that long-term running reduces anxiety and to determine whether this coincides with a change in the expression of the gap junction protein $\mathrm{cx}-36$, additional mice had ad libitum access to a running wheel or were sedentary for 6 weeks, then were tested on the EPM or OF. Following behavioral testing, these mice were perfused and their brains examined for confocal optical intensity of cx-36 labeling in parvalbumin-positive interneurons. To determine whether long-term running for a time period sufficient to reduce anxiety (Schoenfeld et al., 2013) alters theta rhythm, additional mice ran or were sedentary for 3 weeks, after which electrophysiological recordings were made of the vHIP and mPFC.

Animals, drug treatments, and surgery. Adult mice (C57BL/6J, male, 6 weeks old) were used. Gap junctions were blocked with the drugs mefloquine (MQ) and carbenoxolone (CBX). MQ is a selective cx-36 gap junction blocker while CBX is a broad-spectrum gap junction blocker (Cruikshank et al., 2004; Bocian et al., 2009; Bissiere et al., 2011). Control mice were treated with the vehicle (veh) or with chloroquine (CQ) and glycyrrhizic acid (GA), which lack the gap junction-blocking capabilities of MQ and CBX but are structurally similar (Martin and Handforth, 2006). For all experiments, separate groups of mice were used for MQ and CBX infusions. To test whether global blockade of gap junctions alters anxiety, mice $(n=8-13)$ received intraperitoneal injections of MQ (5 mg/kg; National Cancer Institute, \#157387), CBX (15 mg/kg; Sigma), CQ (40 mg/kg; National Cancer Institute, \#14050), or GA (25 mg/kg; National Cancer Institute \#35348) dissolved in 50\% EtOH/saline or the vehicle alone. Drug and vehicle injections were administered $20 \mathrm{~min}$ before behavioral testing, to permit time for the drugs to enter the brain and block gap junctions (Bissiere et al., 2011). Because treatment with the control drugs did not produce the same effects as the gap junction inhibitors, subsequent experiments used only the vehicle as a control. To determine whether peripheral injections alter anxiety-like behavior through blocking gap junctions in the ventral hippocampus, mice received infusions of the drugs ( $100 \mathrm{~mm}$ MQ or $100 \mathrm{~mm} \mathrm{CBX}$ dissolved in $50 \% \mathrm{EtOH} /$ saline) or vehicle directly into the ventral hippocampus on both sides of the brain ( $n=5-6$ for mice tested on EPM; $n=6-7$ for mice tested on OF). To determine whether any effects on anxiety-like behavior were specifically mediated by the vHIP, the drugs (100 mM MQ or $100 \mathrm{~mm}$ CBX dissolved in $50 \% \mathrm{EtOH} /$ saline) or the vehicle were infused bilaterally into the dHIP and behavior was measured ( $n=4$ for mice tested on EPM; $n=4$ for mice tested on OF). To determine whether gap junction signaling in the circuitry involving the vHIP and $\mathrm{mPFC}$ is important for anxiety-like behavior, drugs (100 mM MQ or $100 \mathrm{~mm}$ CBX dissolved in $50 \% \mathrm{EtOH} /$ saline) or the vehicle were infused unilaterally in the vHIP and contralaterally in the mPFC ( $n=7-8$ for mice tested on $\mathrm{EPM} ; n=5-7$ for mice tested on OF). To examine whether unilateral infusions into the vHIP alone were sufficient to alter anxiety-like behavior, drugs or the vehicle were infused into one side of the vHIP and behavior was measured ( $n=4-6$ for mice tested on EPM; $n=6$ for mice tested on OF). Behavior was measured $10 \mathrm{~min}$ following microinfusion, a time point at which following direct injection of drugs into the dHIP blocks gap junctions (Bissiere et al., 2011).

For direct infusion of gap junction inhibitors or vehicle into specific brain regions, cannulae were implanted after mice were anesthetized and placed in a stereotaxic apparatus (David Kopf Instruments). The skull was drilled for placement of cannula and screws. Stereotaxic coordinates for the dHIP, VHIP, and mPFC were based on a report demonstrating a relationship between anxiety-like behavior and correlations of theta rhythm between the vHIP and mPFC (Adhikari et al., 2010). Coordinates for the dHIP implant were as follows: $2.0 \mathrm{~mm}$ posterior from bregma, 2.0 $\mathrm{mm}$ lateral to midline, and $1.5 \mathrm{~mm}$ ventral from the dura. Coordinates for the vHIP implant were as follows: $3.16 \mathrm{~mm}$ posterior from bregma, $3.0 \mathrm{~mm}$ lateral to midline, and 4.2 ventral from the dura. Coordinates for the $\mathrm{mPFC}$ implant were as follows: 1.65 anterior from bregma, $0.5 \mathrm{~mm}$ lateral to midline, $1.5 \mathrm{~mm}$ ventral from the dura. Cannulae were inserted at a depth of $0.5 \mathrm{~mm}$ ventral to the dura-injector needles traveled the remaining distance during microinfusion. Surgical screws were inserted in the skull around the guide cannula, and the cannula (26 gauge, $5 \mathrm{~mm}$ pedestal, $3 \mathrm{~mm}$ tubing length; Plastics One) was lowered into place. Dental acrylic was applied to stabilize and seal the wound, and dummy caps (Plastics One) were used to prevent cannula from clogging. After behavioral analysis (see below), mice were perfused to examine the brains for placement of cannula.

Anxiety tasks. To assess anxiety-like behavior, EPM and OF were used. For the EPM (Walf and Frye, 2007), mice were placed on an elevated (50 $\mathrm{cm})$ plus-shaped track. Two of the arms had high walls $(30 \mathrm{~cm})$ while the other two arms and central intersection were open. All arms were $50 \mathrm{~cm}$ in length, dimly lit by reflected light. Exploratory behavior was measured for $5 \mathrm{~min}$ and analyzed. Number of entries into the open and closed arms and time spent in the open arms were counted for each mouse. More time spent in open arms was deemed indicative of less anxiety. For OF testing (Crawley, 1985), mice explored a $56 \times 56 \mathrm{~cm}$ novel testing box for $10 \mathrm{~min}$ during which time their behavior was videotaped. The numbers of crossings into the center square of the box $(18 \times 18 \mathrm{~cm})$ were counted during the entire session, with more center crossings indicative of less anxiety. In addition, the numbers of crossings that did not involve the center of the box were counted to assess overall locomotion.

Theta recordings. Mice underwent surgery to implant the recording electrodes and a custom-built titanium headplate for head restraint. For the gap junction inhibitor experiments, mice $(n=6-9)$ received an electrode implant in one location-either the vHIP or the mPFC. For the long-term running experiment, mice $(n=6-8)$ received two ipsilateral electrodes implanted in the VHIP and mPFC. Mice were anesthetized and placed in a stereotaxic apparatus. The same coordinates for vHIP and mPFC were used for electrode implantation as were used for cannula implantation (see above). A small craniotomy was made over the site of the chronic electrode implantation. A second craniotomy was made proximal to the implantation site; here, a self-tapping anchor screw (Fine Science Tools) was rotated until tight. A two-lead, single-channel stainless steel electrode (Plastics One) was attached to the stereotaxic positioning arm and lowered so that the polished tip of the electrode contacted the dura. The second lead was bent at a $90^{\circ}$ angle and wrapped around the anchor screw; this lead served as ground. Then, the electrode was lowered through the brain at a rate of $100 \mu \mathrm{m} / \mathrm{min}$, under digital guidance. Each electrode was custom cut to the length necessary to reach the vHIP $(4.2 \mathrm{~mm})$ or the $\mathrm{mPFC}(1.5 \mathrm{~mm})$, so that the electrode connector rested closely on the surface of the skull. Once the electrode was lowered to its target depth, the craniotomy was sealed by a ring of lightcure acrylic. The headplate was positioned around the electrode connector and attached over bregma (vHIP) or the occipital suture (mPFC) with MetaBond. Once the light-cure acrylic and the MetaBond had dried, the skull and anchor screw were covered with a third layer of dental acrylic. Mice were allowed to recover for 1 week before the experiments proceeded. After this time, mice were either subjected to theta recordings before and after gap junction inhibitor injection or after 3 weeks of ad libitum access to a running wheel. At the time of recording, habituation was monitored by video to ascertain when the animal was comfortable with the stationary cylinder, as marked by walking, grooming, and an absence of struggling. Local field potentials (LFPs) were recorded using a differential amplifier (A-M Systems, model 1800). Signals were filtered below $1 \mathrm{~Hz}$ and above $300 \mathrm{~Hz}$ and amplified 100 times. Signals were digitized (National Instruments) at a sampling rate of $1500 \mathrm{~Hz}$ and were recorded using custom MATLAB routines. 
A
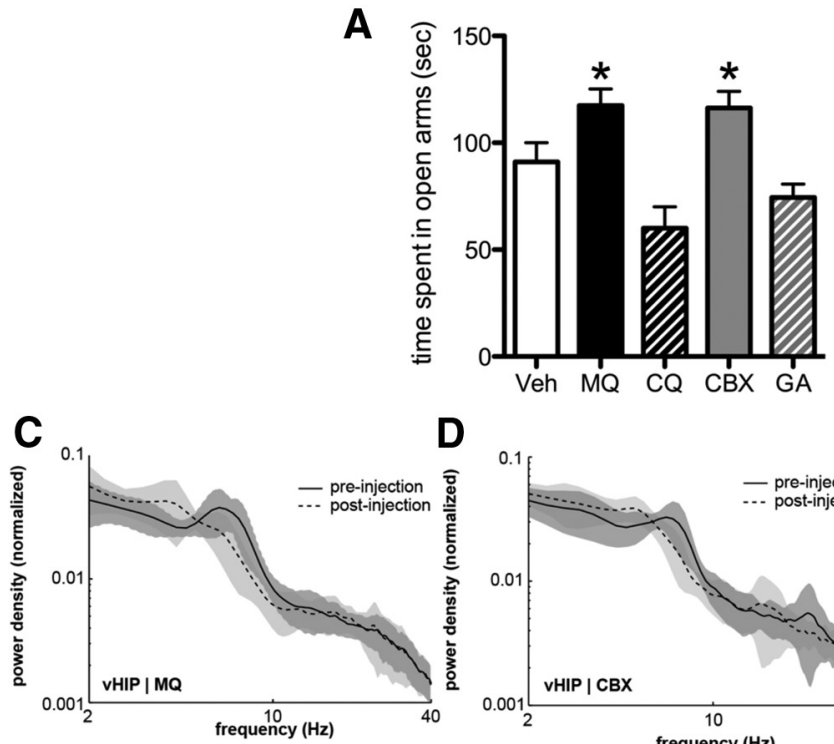

pre munvilumpinyum

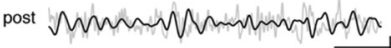

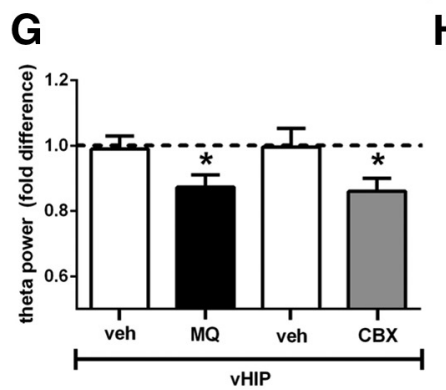

D

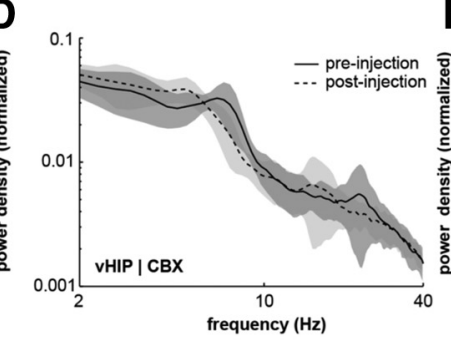

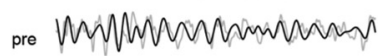

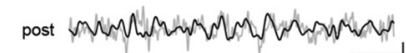

$\mathbf{H}$

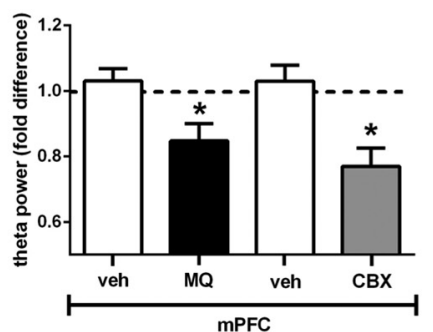

B

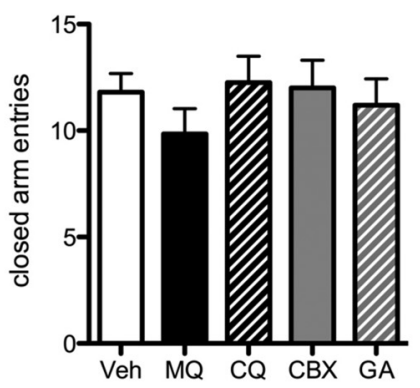

E

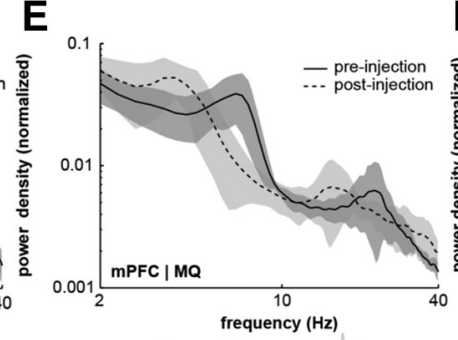

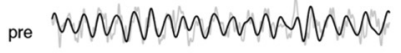
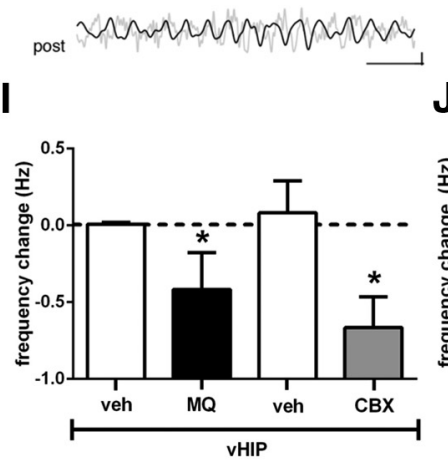

$F$

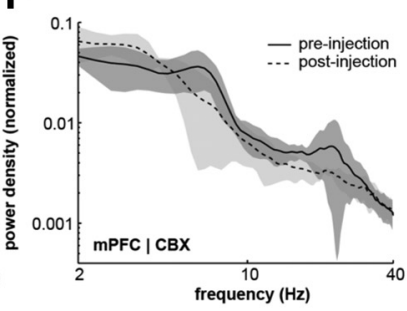

pre Whominthly

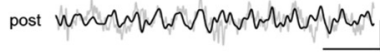
$J$

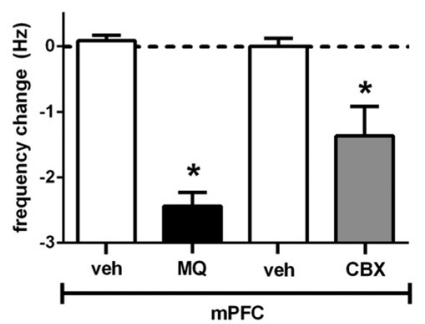

Figure 1. Peripheral blockade of gap junctions reduces anxiety-like behavior and theta activity. $A$, Peripheral injections of $M Q$ or CBX increase time spent in the open arms of the EPM compared with vehicle (Veh) or control drugs ( $C Q$ and $G A ; n=8-13) . \boldsymbol{B}$, Peripheral injections of MQ or CBX do not change the number of closed-arm entries in the EPM. $\boldsymbol{C}-\boldsymbol{F}$, Top, Representative log-log spectra of LFP power density in VHIP with MQ $(\boldsymbol{C})$ or CBX (D) injection and $\mathrm{mPFC}$ with MQ $(\boldsymbol{E})$ and $\mathrm{CBX}(\boldsymbol{F})$ injection. Solid line with dark gray shading: mean preinjection recording with $95 \%$ confidence interval. Dashed line with light gray shading: mean postinjection recording with $95 \%$ confidence interval. Bottom, Representative LFP traces from individual animals pre and post $M Q$ injections. Gray line, LFP filtered between 1 and $50 \mathrm{~Hz}$; black line, theta-filtered LFP (3-15 Hz). Calibration: Horizontal, $500 \mathrm{~ms}$, vertical, $0.2 \mathrm{mV}$. G, $\boldsymbol{H}, \mathrm{MQ}$ and $\mathrm{CBX}$ reduce theta power in vHIP (G) and mPFC (H); fold decreases are relative to theta power during preinjection for each condition $(n=6-7) . I, J, \mathrm{MQ}$ and $C B X$ reduce peak theta frequency in $v H I P(I)$ and $\mathrm{mPFC}(J)$ for each condition $(n=6-7) ;{ }^{*} p<$ 0.05 compared with Veh. Error bars indicate SEM.

Either 1 week after surgery for the gap junction inhibitor experiment or 4 weeks after surgery for the 3 week running experiment, the mouse was head fixed atop the stationary wheel; its behavior was monitored and LFP signals were recorded for $15 \mathrm{~min}$. During the first $10 \mathrm{~min}$ of recording, mice ran at will. During the last $5 \mathrm{~min}$ of the recording, running was encouraged by nudging the running wheel, which resulted in 10-20 s bouts of running. In the runner versus sedentary experiments, the recordings stopped here. In the experiments testing gap junction-blocking drugs, the experiments proceeded. The vehicle was then injected intraperitoneally and the animal was allowed to rest for $10 \mathrm{~min}$. Then, the mouse's behavior and LFP signals were recorded for $15 \mathrm{~min}$, as described above. MQ or CBX was injected intraperitoneally and the animal was allowed to rest for $20 \mathrm{~min}$. Finally, the mouse's behavior and LFP signals were recorded as before, for $15 \mathrm{~min}$, as described above $(n=6-8)$. In all experiments, movement artifacts were removed from the dataset by hand.

Power spectral density estimates for LFP signals were generated by downsampling the LFP signal to $100 \mathrm{~Hz}$ and using the MATLAB routines for Welch's method ("pwelch") over a Hanning window of $0.5 \mathrm{~s}$ with $50 \%$ overlap using 256 FFTs. Each spectrum was then normalized by the sum of the power in the overall signal. The resulting spectral density estimates were fit to the sum of a decaying exponential and a Gaussian using MATLAB's Curve Fitting Toolbox ("cftool"; Adhikari et al., 2010). The center of the Gaussian was constrained to fall within theta $(3-15 \mathrm{~Hz})$.
To reliably estimate theta, the center of the resulting Gaussian at its mean was reported as the peak theta frequency, and the area under the resulting Gaussian was reported as the theta power. In the drug experiments, postinjection theta measurements were reported as fractions of theta power preinjection measurements ("fold difference") to compare the effect of the drug against a vehicle. In the free running experiments, the total theta power was reported as the area under the resulting Gaussian.

Once the experiments were completed, mice were transcardially perfused and their brains examined to verify electrode placement.

Running, immunolabeling, confocal optical intensity analysis and theta recording. Mice were group housed in a standard laboratory cage with or without access to a running wheel for 6 weeks. After 6 weeks of running, the wheels were closed and the mice were tested after a $24 \mathrm{~h}$ waiting period. Mice were not tested immediately after having access to the running wheel to eliminate any acute effects of running. After the $24 \mathrm{~h}$ waiting period, mice were subjected to anxiety testing as described above (different groups of mice were tested in EPM, $n=9-10$, and OF, $n=$ $9-10)$. Immediately after anxiety testing, mice were perfused and the brains processed for combined parvalbumin (PV) and cx-36 staining. PV was selected as an inhibitory interneuron marker because within the hippocampus, $\mathrm{PV}+$ cells include basket cells, which express cx-36 and are known to participate in the generation of theta rhythm (Buzsáki, 2002; Connors and Long, 2004; Collignon et al., 2006). The expression of 
cx-36 in PV-interneurons was measured using immunofluorescence and confocal optical intensity analysis.

For colabeling with PV and cx-36 immunofluorescence, free-floating sections through the hippocampus and $\mathrm{MPFC}$ were rinsed in $0.1 \mathrm{M}$ TBS, $\mathrm{pH} 7.5$, incubated in 3\% normal goat serum (Vector Laboratories), incubated with mouse anti-PV (1:1000; Sigma) plus rabbit anti-cx-36 (1 $\mu \mathrm{g} / \mathrm{ml}$ with $0.5 \%$ Tween 20 ; Invitrogen), and stored at $4^{\circ} \mathrm{C}$. Two days later, sections were rinsed and incubated in goat anti-mouse Alexa 568 (1:500; Invitrogen) to visualize parvalbumin and goat anti-rabbit Alexa 488 (1:500; Invitrogen) to visualize cx-36, in the dark for $60 \mathrm{~min}$. Sections were rinsed and mounted onto SuperFrost slides, and coverslipped using glycerol in TBS (3:1). Slides were kept in the dark at $4^{\circ} \mathrm{C}$ until microscopic analyses.

Slides were coded until completion of the data analysis. Optical intensity of cx-36 in PVinterneurons was examined using a Zeiss Axiovert confocal laser scanning microscope ( 510 LSM; lasers are argon 458/488 and HeNe 543). For each PV-interneuron in the granule cell layer and CA3 and CA1 regions of the vHIP and dHIP as well as the mPFC, $1 \mu \mathrm{m}$ optical slices were scanned and the cell body traced using the measurement tool in the Zeiss 510 LSM software. For each area in each brain, 10 PV-interneurons were analyzed. The optical intensity of cx-36 was determined for each cell. Raw intensity values were divided by background intensity on the same scan of each slice to control for variability in staining intensity between sections (Kozorovitskiy et al., 2005).

Additional groups of mice were used for electrophysiology recordings of theta rhythm in the vHIP and mPFC after long-term running. After electrode implantation followed by a 1 week recovery period (see above), mice were group housed in a standard laboratory cage with or without access to a running wheel for the next 3 weeks. Because long duration periods of running lead to the loss of head plates and electrodes in this apparatus, we selected the shortest time period of running that reliably produces an anxiolytic effect in the EPM tests (Schoenfeld et al., 2013), 3 weeks. After 3 weeks of running, the wheels were closed and the mice were habituated to the recording conditions on the following day for a period of $45 \mathrm{~min}$. The day after habituation, theta recordings were obtained as described above.

Statistics. For the anxiety tests, one-way ANOVA was used followed by Fisher LSD post hoc comparisons. For the running connexin-36 study, unpaired Student's $t$ tests were used. For the theta recordings, paired $t$ tests were used when comparing fold differences in theta between states and peak theta frequency. For the running theta experiment, unpaired $t$ tests were used. Data presented in the text are summarized as mean \pm SEM.

\section{Results}

Gap junction blockers decrease anxiety-like behavior and reduce theta power in the VHIP and $\mathrm{mPFC}$

Global treatment with either MQ or CBX reduced anxiety-like behavior as measured by increased time spent in the open arms of the EPM compared with any of the other treatments $\left(F_{(4,46)}=\right.$ $9.28, p=0.0001$; Fig. $1 A)$. These effects are likely due to reduced
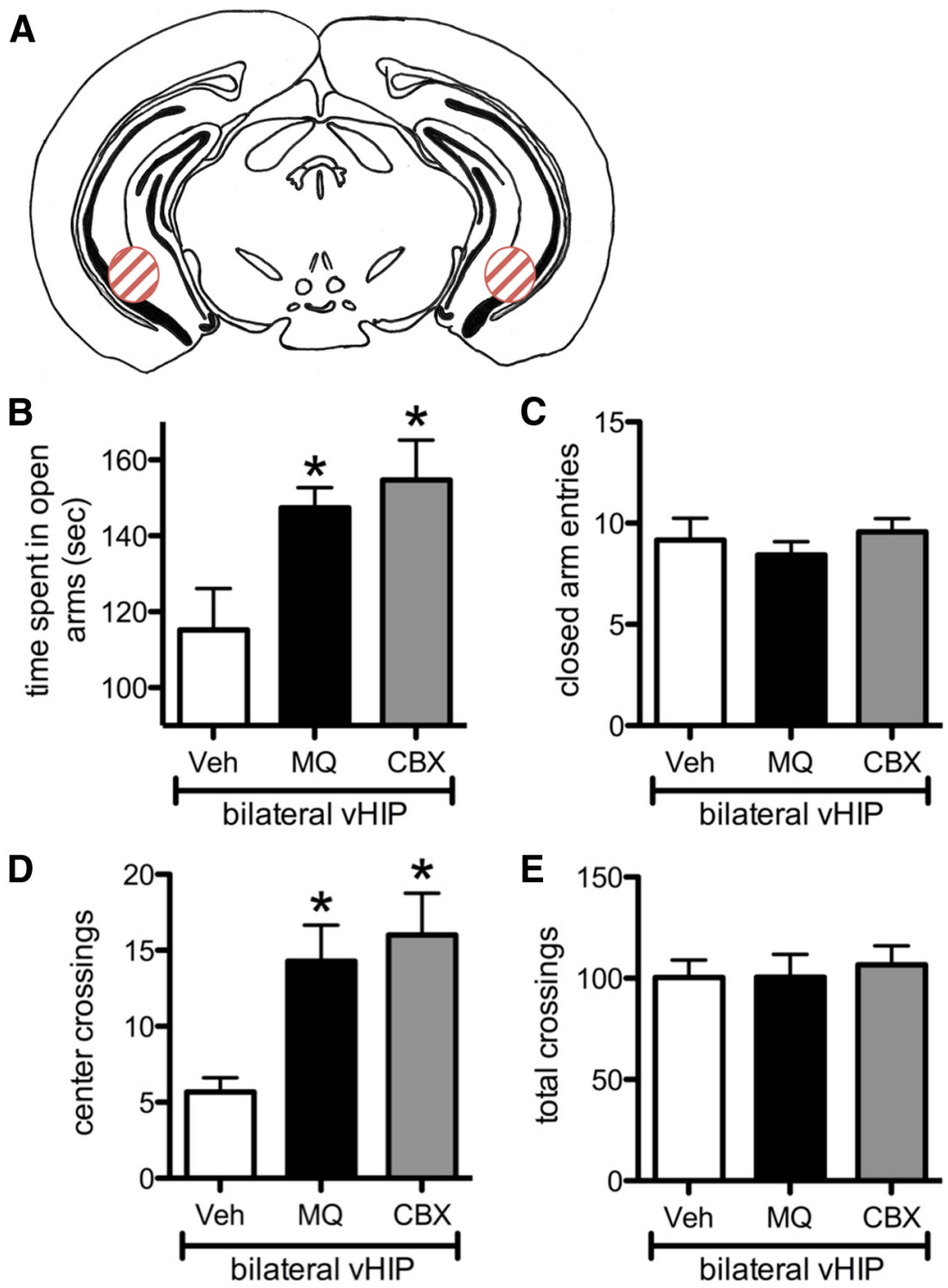

Figure 2. Blockade of gap junctions in the bilateral vHIP reduces anxiety-like behavior. $A$, Brain atlas section shows location of injection (red striped circles; adapted from Franklin and Paxinos, 2008). $\boldsymbol{B}, \boldsymbol{D}$, Infusion of MQ or CBX into the vHIP reduces anxietyke behavior on the EPM (time spent in open arms, $\boldsymbol{B} ; n=5-6$ ) and $O F$ (number of center crossings, $\boldsymbol{D} ; n=6-7$ ). $\boldsymbol{C}, \boldsymbol{E}$, Infusion of $M Q$ or CBX in the vHIP does not affect locomotion measures in the EPM (closed-arm entries, $\boldsymbol{C}$ ) or OF (total crossings, $\boldsymbol{E}$ ). For all graphs, ${ }^{*} p<0.05$ compared with Veh. Error bars indicate SEM.

anxiety rather than changes in general locomotion because there were no changes in the overall number of closed-arm entries $\left(F_{(4,46)}=0.73, p=0.57\right.$; Fig. $\left.1 B\right)$.

Similar to what has been observed with gap junction blockade in the dHIP (Bissiere et al., 2011), treatment with MQ or CBX altered theta rhythm in vHIP and $\mathrm{mPFC}$ (Fig. $1 C-F$ ). To measure the effects of these drugs on theta rhythm, we examined two parameters of theta: peak frequency and total power. Both parameters were found to be decreased with both drugs in both brain regions. We estimated these parameters from curves fit to power spectra (see Materials and Methods; Adhikari et al., 2010). In mice running freely on a stationary treadmill, peripheral MQ injection reduced the peak theta frequency from $6.36 \pm 0.18$ to $5.23 \pm 0.31 \mathrm{~Hz}$ in the vHIP $\left(t_{(6)}=-4.1415, p=0.006\right)$ and from $6.25 \pm 0.38$ to $3.91 \pm 0.37 \mathrm{~Hz}$ in the $\operatorname{mPFC}\left(t_{(5)}=-9.68, p=\right.$ $0.0002)$, and peripheral CBX injection reduced the peak theta frequency from $6.30 \pm 0.96$ to $5.57 \pm 0.97 \mathrm{~Hz}$ in $\operatorname{vHIP}\left(t_{(5)}=\right.$ $-3.33, p=0.02)$ and from $6.26 \pm 0.43$ to $4.52 \pm 0.31 \mathrm{~Hz}$ in $\operatorname{mPFC}\left(t_{(6)}=-3.00, p=0.03\right)$. Vehicle injections did not reduce 


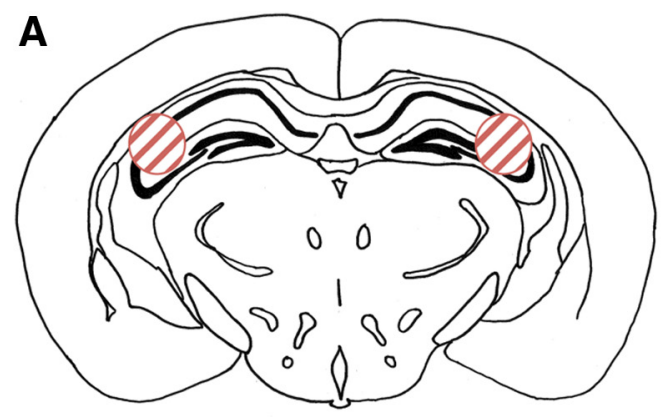

B

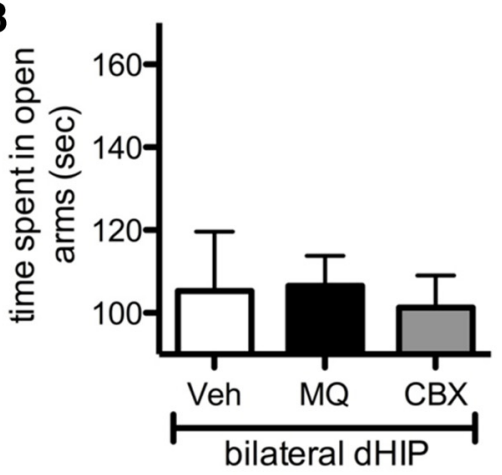

D

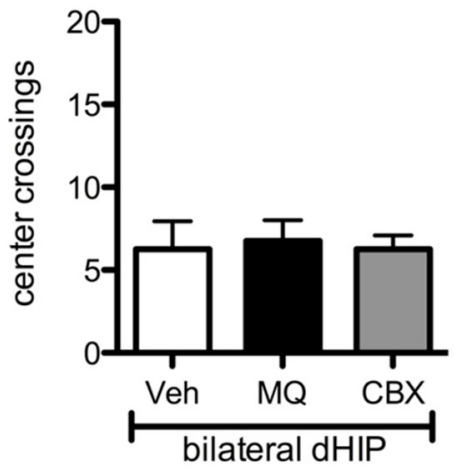

C
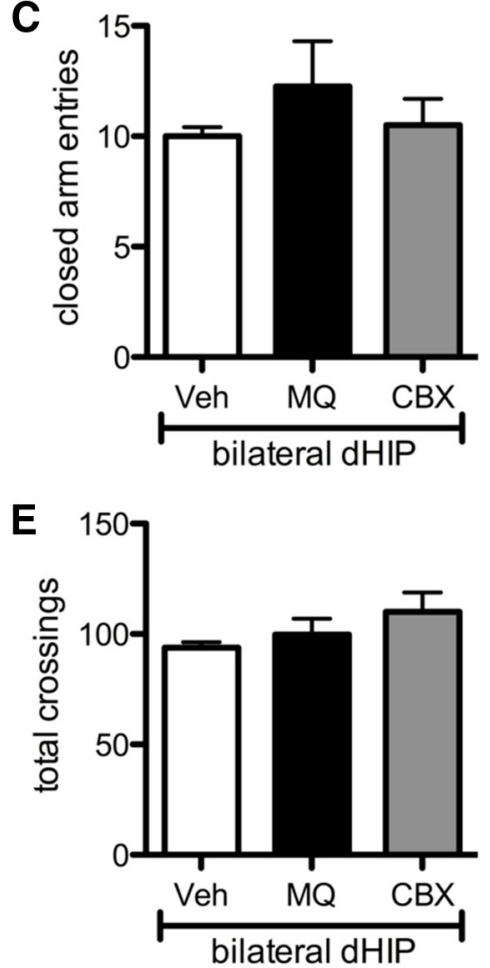

Figure 3. Blockade of gap junctions in the bilateral dHIP does not affect anxiety-like behavior. $\boldsymbol{A}$, Brain atlas section shows location of injection (red striped circles; adapted from Franklin and Paxinos, 2008). B, D, Infusion of MQ or CBX into the dHIP does not change anxiety-like behavior on the EPM (time in open arms, $\boldsymbol{B} ; n=4$ ) and OF (number of center crossings, $\boldsymbol{D} ; n=4$ ). $\boldsymbol{C}, \boldsymbol{E}$, Infusion of MQ or CBX in the dHIP does not affect locomotion measures in the EPM (closed-arm entries, $\boldsymbol{C}$ ) or OF (total crossings, $\boldsymbol{E}$ ). Error bars indicate SEM.

the peak frequency in either vHIP $\left(t_{(11)}=-0.22, p=0.82\right)$ or $\operatorname{mPFC}\left(t_{(9)}=1.83, p=0.12\right.$; Fig. $\left.1 I, J\right)$. In all cases, alterations to theta frequency were accompanied by significant decreases in the theta power. Peripheral MQ injection reduced the theta power relative to vehicle in the vHIP $\left(t_{(6)}=-4.86, p=0.003\right)$ and in the $\operatorname{mPFC}\left(t_{(5)}=-5.03, p=0.004\right)$, and peripheral CBX injection reduced theta power relative to vehicle in the $\operatorname{vHIP}\left(t_{(5)}=-3.02\right.$, $p=0.03)$ and in the $\operatorname{mPFC}\left(t_{(6)}=-4.01, p=0.007\right)$; vehicle injections did not alter theta power in the $\operatorname{vHIP}\left(t_{(11)}=0.32, p=\right.$ $0.75)$ or $\operatorname{mPFC}\left(t_{(9)}=0.17, p=0.87\right.$; Fig. $\left.1 G, H\right)$.

When mice were resting on the treadmill, peripheral injections were effective at reducing theta peak frequency in the vHIP (MQ: $5.83 \pm 0.44$ to $4.74 \pm 0.53 \mathrm{~Hz}, t_{(6)}=2.97, p=0.03$; CBX: $5.38 \pm 0.24$ to $\left.4.90 \pm 0.61 \mathrm{~Hz}, t_{(5)}=-3.00, p=0.03\right)$ and $\mathrm{mPFC}$ (MQ: $5.92 \pm 0.36$ to $3.79 \pm 0.34, \mathrm{HZ}_{(5)}=-4.57, p=0.006$; CBX: $6.09 \pm 0.35$ to $4.52 \pm 0.74 \mathrm{~Hz}, t_{(6)}=-2.61, p=0.04$ ) compared with vehicle; vehicle injection did not reduce the peak frequency in either vHIP $\left(t_{(11)}=0.46, p=0.65\right)$ or $\operatorname{mPFC}\left(t_{(9)}=\right.$ $0.58, p=0.57)$. These injections were also effective at reducing theta power in vHIP (MQ: $-24.9 \pm 6.4 \%$, $t_{(6)}=-3.95, p=0.0075 ; \mathrm{CBX}:-14.1 \pm$ $\left.6.6 \%, t_{(5)}=-2.62, p=0.047\right)$ and in the mPFC (MQ: $-16.3 \pm 4.2 \%, t_{(5)}=-3.41$, $p=0.019$; CBX: $-29.1 \pm 9.9 \%, t_{(6)}=$ $-2.61, p=0.04)$ compared with vehicle; vehicle injections did not reduce the theta power in either vHIP $\left(t_{(11)}=0.73, p=\right.$ $0.48)$ or $\operatorname{mPFC}\left(t_{(9)}=0.69, p=0.51\right)$.

Direct injections of gap junction blockers into the vHIP and mPFC decrease anxiety-like behavior Bilateral infusion of either MQ or CBX into the vHIP reduced anxiety-like behavior on both the EPM and OF compared with bilateral infusion of the vehicle $\left(\mathrm{EPM}: F_{(2,14)}=4.88, p=0.03\right.$; OF: $F_{(2,17)}=5.65, p=0.01$; Fig. $\left.2 A, B, D\right)$. These treatments did not alter overall locomotion in either the EPM or OF, just time spent in the more anxiety-provoking parts of each apparatus (EPM: $F_{(2,17)}=$ $0.57, p=0.57$; OF: $F_{(2,17)}=0.13, p=0.87$; Fig. 2C,E). Bilateral infusion of either MQ or CBX into the dHIP did not alter anxiety-like behavior on either EPM or OF (EPM: $F_{(2,9)}=0.07, p=0.93$; OF: $F_{(2,9)}=0.05, p=0.95$; Fig. $\left.3 A, B, D\right)$ nor did it affect overall locomotion on either apparatus (EPM: $F_{(2,9)}=0.72, p=0.51$; OF: $F_{(2,17)}=1.48, p=0.28$; Fig. $\left.3 C, E\right)$.

Unilateral infusion of $\mathrm{MQ}$ or $\mathrm{CBX}$ into the vHIP and contralateral infusion of the same drug into the mPFC had a similar effect as bilateral infusion of these drugs into the vHIP alone. That is, vHIP-mPFC gap junction blockade reduced anxietylike behavior (EPM: $F_{(2,19)}=3.64, p=$ 0.046; OF: $F_{(2,15)}=4.23, p=0.035$; Fig. $4 A, B, D)$ without altering overall locomotion $\left(\mathrm{EPM}: F_{(2,19)}=2.19, p=0.14\right.$; OF: $F_{(2,15)}=0.09, p=0.92$; Fig. $\left.4 C, E\right)$. To examine whether the anxiolytic effects of vHIP/mPFC gap junction blockade were caused by unilateral injections into the vHIP alone, we also examined the effects of unilateral vHIP infusion of gap junction blockers on EPM and OF behavior. No effects of unilateral injections of MQ or CBX in the ventral hippocampus on anxiety-like behavior in the EPM and OF (EPM: $F_{(2,13)}=0.10, p=0.91$; OF: $F_{(2,15)}=0.03, p=$ 0.97; Fig. $5 A, B, D)$ nor general locomotion (EPM: $F_{(2,13)}=0.11$, $p=0.89$; OF: $F_{(2,15)}=0.30, p=0.74$; Fig. $\left.5 C, E\right)$ were observed.

\section{Running reduces connexin-36 expression in the vHIP but not theta oscillations}

Consistent with previous results showing an anxiolytic effect of exercise (Duman et al., 2008; Trejo et al., 2008; Salam et al., 2009; Schoenfeld et al., 2013), 6 weeks of running produced a significant reduction in anxiety-like behavior on the EPM and OF compared with sedentary mice. Running increased the amount of time spent in the open arms of the EPM $\left(t_{(17)}=2.15, p=0.046\right)$ and number of center crossings in the $\mathrm{OF}\left(t_{(16)}=2.40, p=0.029\right)$ and no difference in overall locomotion, either the number of 
closed-arm entries in the EPM $\left(t_{(17)}=\right.$ $0.34, p=0.74)$ or total crossings in the $\mathrm{OF}$ $\left(t_{(16)}=0.30, p=0.77\right)$.

Optical intensity of confocal immunofluorescent images was used to compare cx-36 expression in PV + cells of runners versus sedentary mice (Fig. 6A). These analyses revealed that, compared with sedentary mice, runners exhibit a reduction in cx-36 expression throughout the vHIP, including in the dentate gyrus and CA3 and CA1 regions (DG: $t_{(15)}=3.24$, $p=0.01$; CA3: $t_{(16)}=4.34, p=0.01$; CA1: $t_{(16)}=5.58, p=0.01$; Fig. $6 A$ ). In contrast, no change in $\mathrm{cx}-36$ expression in $\mathrm{PV}+$ cells was observed in the mPFC of runners compared with sedentary mice $\left(t_{(15)}=\right.$ 0.26, $p=0.80$; Fig. $6 B$ ). Likewise, no change in cx-36 expression in PV + cells was observed in the dentate gyrus and CA3 and CA1 regions of the dHIP (DG: $t_{(15)}=1.6, p=0.13$; CA3: $t_{(15)}=0.97, p=$ 0.35 ; CA1: $\left.t_{(15)}=0.01, p=0.92\right)$.

Three weeks of running, a time point also known to reduce anxiety on the EPM (Schoenfeld et al., 2013), produced no changes in theta oscillations (Fig. 6D,E). During free locomotion on the wheel, there was no significant difference in the peak frequency of theta between the runner and control groups for the vHIP (runner, $6.47 \pm 0.51 \mathrm{~Hz}$; control, $7.03 \pm 0.21$ $\mathrm{Hz} ; t_{(10)}=0.96, p=0.30$ ) or mPFC (runner, $6.56 \pm 0.78 \mathrm{~Hz}$; control, $6.71 \pm 0.67$ $\left.\mathrm{Hz} ; t_{(10)}=0.61, p=0.55\right)$. Moreover, there was no discernible difference in the power within the theta band in either the vHIP (runner, $0.21 \pm 0.01$; control, $\left.0.20 \pm 0.006 ; t_{(10)}=0.46, p=0.87\right)$ or mPFC (runner, 0.22 \pm 0.01 ; control, $\left.0.23 \pm 0.006 ; t_{(10)}=0.611, p=0.46\right)$ between the runner and control groups (Fig. $6 C, D)$. A similar lack of difference was observed for the resting condition for peak frequency (vHIP: runner, $4.02 \pm 0.5 \mathrm{~Hz}$, control, $4.22 \pm 0.70 \mathrm{~Hz}, t_{(10)}=0.24, p=$ 0.82 ; mPFC: runner, $3.91 \pm 0.39 \mathrm{~Hz}$, control, $\left.3.78 \pm 0.13 \mathrm{~Hz}, t_{(10)}=0.32, p=0.76\right)$ and theta power (normalized units; vHIP: runner, $0.22 \pm 0.01$, control, $0.23 \pm 0.007, t_{(10)}=0.68, p=0.46$; mPFC: runner, $0.23 \pm 0.006$, control, $0.23 \pm 0.006, t_{(10)}=0.168$, $p=0.87)$.

\section{Discussion}

The results of these experiments strongly suggest that gap junction signaling within the vHIP-mPFC pathway modulates anxiety. Peripheral injections of gap junction blockers mefloquine and carbenoxolone reduced anxiety-like behavior on the elevated plus maze and open field compared with their respective control drugs. Since studies using a variety of methodologies, including lesion, electrophysiological recordings, temporary inactivation, and pharmacological manipulations, suggest that the rodent vHIP plays a role in anxiety regulation (Adhikari et al., 2010; Prelimbic; Cg1, cingulate.
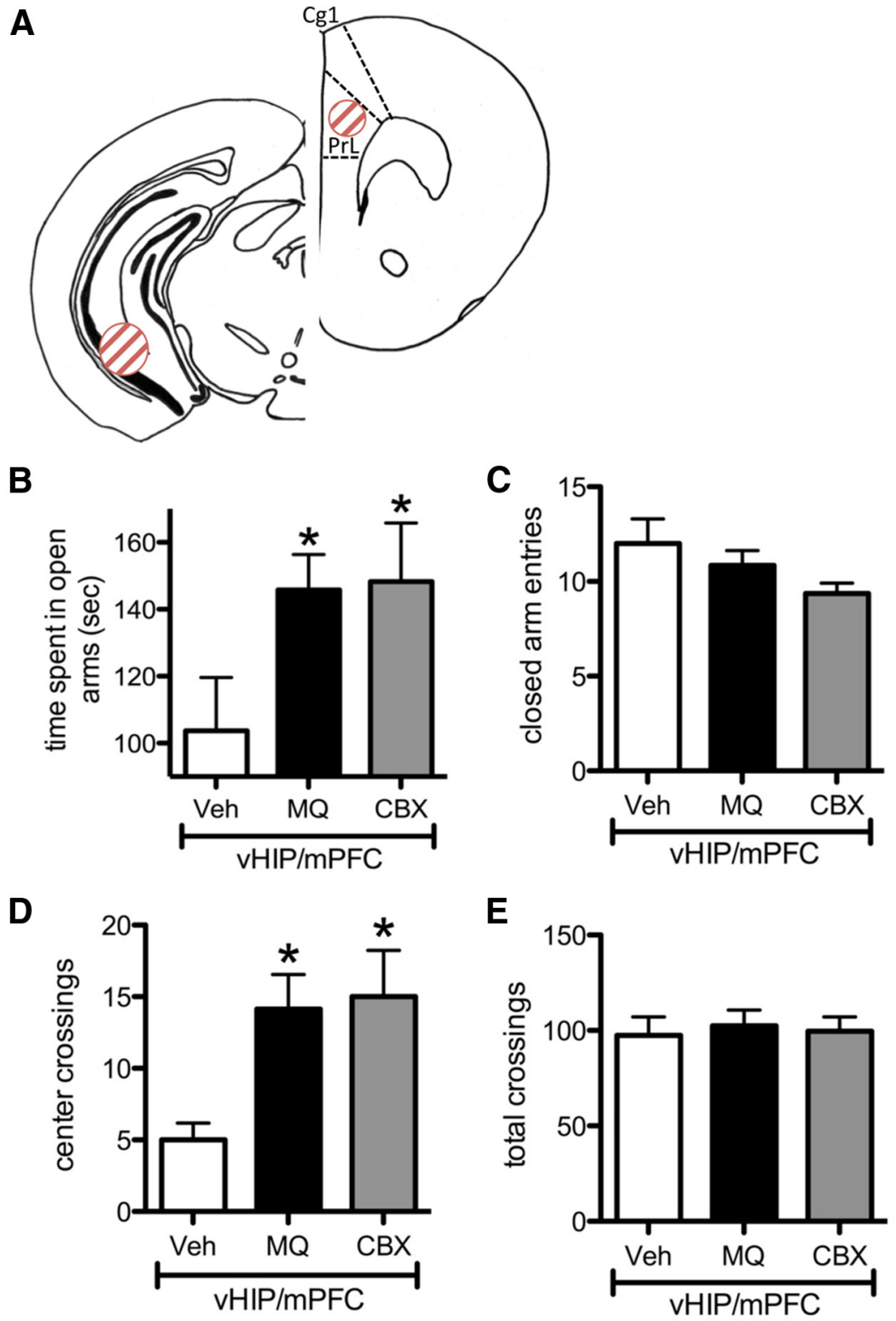

Figure 4. Blockade of gap junctions in the $\mathrm{VHIP} / \mathrm{mPFC}$ pathway reduces anxiety-like behavior. $\boldsymbol{A}$, Brain atlas sections show location of injections (red striped circles; adapted from Franklin and Paxinos, 2008). $\boldsymbol{B}, \boldsymbol{D}$, Infusion of MQ or (BX into the vHIP unilaterally, and the mPFC contralaterally reduces anxiety-like behavior on the EPM (time in open arms, $\boldsymbol{B} ; n=7-8$ ) and $0 \mathrm{~F}$ (number of center crossings, $\boldsymbol{D} ; n=5-7) \boldsymbol{C}, \boldsymbol{E}$, Infusion of MQ or CBX in the vHIP/mPFC does not affect locomotion measures in the EPM (closed-arm entries, $\boldsymbol{C}$ ) or OF (total crossings, $\boldsymbol{E}$ ). For all graphs, ${ }^{*} p<0.05$ compared with Veh. Error bars indicate SEM. Prl,

Fanselow and Dong, 2010; McEown and Treit, 2010, 2011,2013), we delivered gap junction blockers directly into the vHIP on both sides of the brain and examined anxiety-like behavior. Injections of both gap junction blockers reduced anxiety-like behavior on both tasks compared with vehicle injection. This effect was specific to the ventral portions of the hippocampus, as injections of gap junction blockers into the dorsal region of the hippocampus had no effect on anxiety-like behavior on either task. The lack of an anxiolytic effect of gap junction blocker infusion into the dHIP is perhaps not surprising given that the vHIP has been implicated in anxiety regulation while the $\mathrm{dHIP}$ has been more closely linked to the memory functions of the hippocampus, including but not limited to context fear conditioning (Bannerman et al., 2003; Fanselow and Dong, 2010; McEown and Treit, 2010, 2011, 2013). 
A

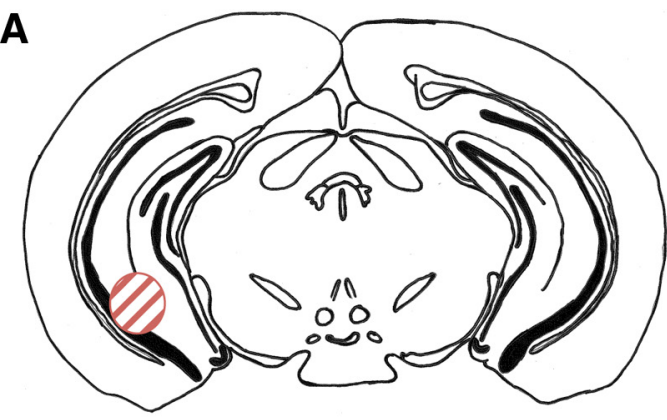

B

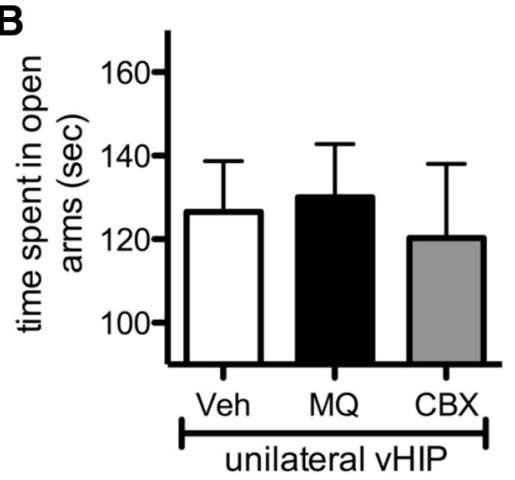

D

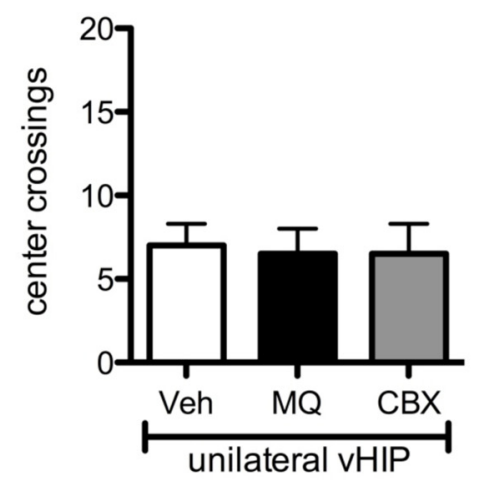

C

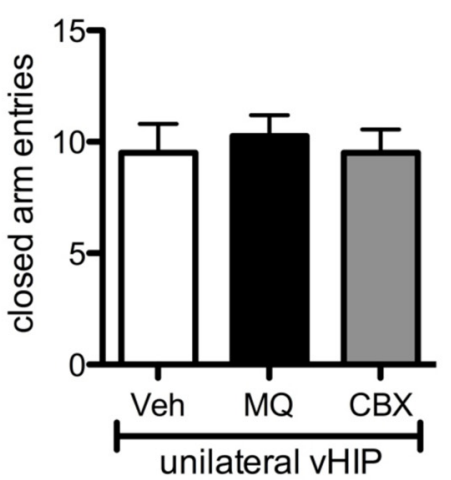

E

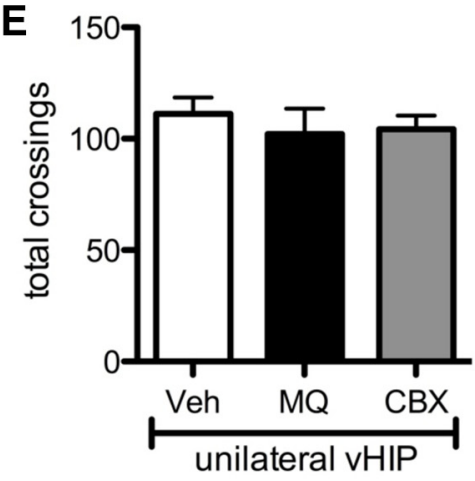

Figure 5. Blockade of gap junctions in the unilateral vHIP does not affect anxiety-like behavior. $\boldsymbol{A}$, Brain atlas section shows location of injection (red striped circle; adapted from Franklin and Paxinos, 2008). $\boldsymbol{B}, \boldsymbol{D}$, Infusion of MQ or CBX into the unilateral vHIP does not change anxiety-like behavior on the EPM (time in open arms, $\boldsymbol{B} ; n=4-6$ ) and OF (number of center crossings, $\boldsymbol{D}$; $n=6) . C, E$, Infusion of MQ or CBX in the unilateral vHIP does not affect locomotion measures in the EPM (closed-arm entries, $\boldsymbol{C}$ ) or OF (total crossings, $\boldsymbol{E}$ ). Error bars indicate SEM.

Because synchronous activity between the vHIP and mPFC is correlated with anxiety-like behavior (Adhikari et al., 2010), we investigated the role of gap junction signaling in the vHIP-mPFC pathway in anxiety-like behavior. By injecting gap junction blockers unilaterally into the vHIP, and contralaterally into the mPFC, we mimicked the anxiolytic effect of bilateral vHIP injections of gap junction blockers. The results suggest that electrical signaling, which generates synchronous activity between the vHIP and mPFC, drives anxiety-like behavior and not necessarily activity alone in either region. To verify that unilateral vHIP gap junction blockade was not sufficient to reduce anxiety, we injected mefloquine and carbenoxolone into the vHIP on one side, and saw no effect on anxiety-like behavior. This latter experiment shows that blockade of gap junction signaling on both sides of the brain is necessary to lower anxiety-like behavior.

Several lines of evidence suggest that hippocampal and mPFC theta activity mediates anxiety-like behavior. First, the 5-HT1A receptor knock-out mouse has increased hippocampal theta power and increased anxiety-like behavior (Gordon et al., 2005).

Second, increased theta activity in the vHIP and mPFC correlates with more anxious behavior (Adhikari et al., 2010). Third, anti-anxiety drugs have been shown to disrupt hippocampal theta (Zhu and McNaughton, 1994; Yeung et al., 2012, 2013a; Wells et al., 2013) although these latter studies have focused on the dHIP. Together with the data from the present report, these findings suggest that blocking gap junctions may reduce anxiety-like behavior by disruption of synchronous theta activity between hippocampal and $\mathrm{mPFC}$ neurons. Our findings further suggest that synchronous theta activity in the vHIP-mPFC pathway on just one side is sufficient to maintain baseline control levels of anxiety-like behavior.

It is important to note that drug treatments that increase anxiety, including yohimbine, do not appear to increase theta power (Yeung et al., 2013b). While those results may seem contradictory and raise the possibility of mechanisms for anxiety regulation above and beyond the modulation of theta rhythm, it is relevant that the previous work focused on dHIP and not vHIP or mPFC. Since the vHIP and mPFC have been relatively unexplored with regard to the question of theta rhythm and anxiety, the question remains open of whether anxiogenic manipulations increase theta oscillations in functionally relevant brain regions.

Running is anxiolytic in mice (Duman et al., 2008; Schoenfeld et al., 2013), raising the possibility that this effect is mediated by diminished gap junction signaling. We first verified that long-term running reduces anxiety-like behavior by examining the behavior of mice on the EPM and OF after 6 weeks of running compared with sedentary controls. To measure cx-36 expression in runners and sedentary mice, we obtained optical intensity of $\mathrm{cx}-36$ protein on parvalbumin interneurons in the vHIP and mPFC. PVinterneurons have been suggested to play an important role in generating theta rhythms (Dragoi et al., 1999; Klausberger et al., 2003), and oscillatory activity in the vHIP and mPFC has been shown to decrease as a result of a reduction in PV-interneurons (Lodge et al., 2009). We found a reduction in cx-36 optical intensity on PV-interneurons in the dentate gyrus, CA3, and CA1 regions of the vHIP in runners, but no change in the dHIP or mPFC. These findings raise the possibility that running reduces anxiety, at least in part, by decreasing expression of $\mathrm{cx}-36$ specifically in the PV+ containing interneurons of the vHIP. Since cx-36 is involved in neuron-neuron gap junction signaling, a decrease in this protein seems likely to reduce basket cell coupling and ensuing theta oscillations. However, our results suggest that a 3 week running period, a time sufficient to induce an anxiolytic effect (Schoenfeld et al., 2013), produces no change in central frequency or power in the theta range from vHIP or mPFC. It is possible that a longer running time duration would produce 
A

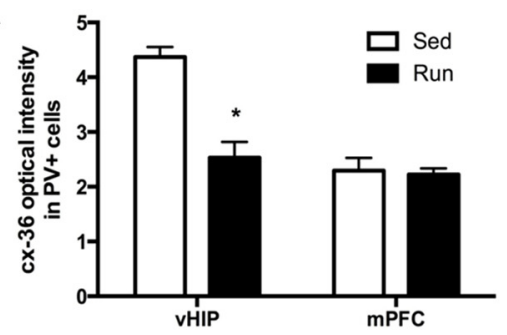

B

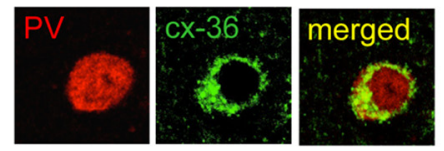

C

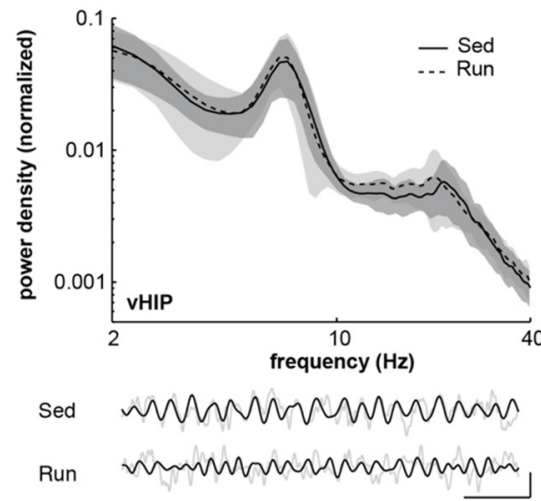

D

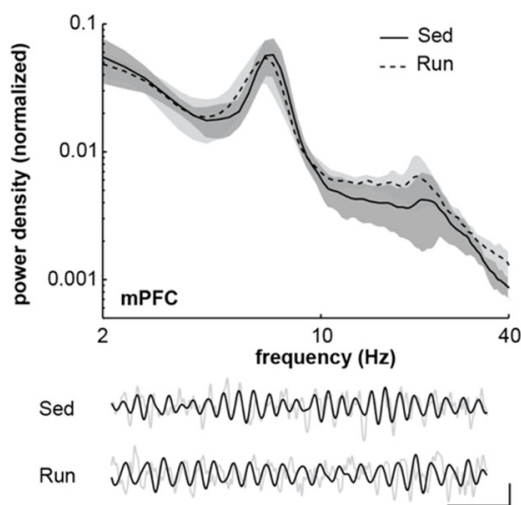

Figure 6. Running reduces neuronal connexin-36 expression in the vHIP but not theta oscillations. $A$, Running (Run) reduces confocal optical intensity for cx-36 in PV-positive cells of the vHIP, but not in the mPFC $(n=8-9)$. Data for vHIP are from CA1, but similar findings were observed for dentate gyrus and CA3 (see text); ${ }^{*}<0.05$ compared with sedentary controls (Sed). $\boldsymbol{B}$, Representative confocal images show a putative basket cell in the ventral CA1 region that is positive for PV (red) and cx-36 (green). Scale bar, $10 \mu \mathrm{m}$. C, D, Top, Representative log-log spectra of LFP power density in $\operatorname{VIIP}(\boldsymbol{C})$ and $\mathrm{mPFC}(\boldsymbol{D})$ between Run and Sed control groups. Sold line with dark gray shading: mean sedentary control recording with $95 \%$ confidence interval. Dashed line with light gray shading: mean runner recording with $95 \%$ confidence interval. Bottom, Representative LFP traces from individual animals from Run and Sed control groups. Gray line, LFP filtered between 1 and $50 \mathrm{~Hz}$; black line, theta-filtered LFP ( $3-15 \mathrm{~Hz}$ ). Calibration: horizontal: $500 \mathrm{~ms}$, vertical, $0.2 \mathrm{mV}$. Error bars indicate SEM.

changes in basal theta activity in vHIP and mPFC, but because 3 weeks of running is anxiolytic in mice, it is likely that the anxiolytic actions of this duration of running involve an additional mechanism, such as the augmentation of GABAergic inhibition (Schoenfeld et al., 2013), in addition to any potential effect on gap junction channels. It is also possible that any effect of running on theta rhythms in vHIP and mPFC is more pronounced during anxiety-provoking conditions and future studies should examine potential differences in theta between runners and sedentary animals during tests of anxiety, where theta power in vHIP and $\mathrm{mPFC}$ is increased (Adhikari et al., 2010). Our findings do suggest though that running produces changes in the expression of gap junction channels on PV cells in the ventral hippocampus, but it is still unclear whether such changes are functionally significant. If these connexin expression changes do affect theta rhythms, it is also possible that these changes in the vHIP would induce changes in theta rhythm in the MPFC without altering mPFC cx-36 expression. Indeed, it has been suggested that patterned activity in prefrontal neurons may be driven more by ventral hippocampal projections than by local interneuron activity (Jones and Wilson, 2005; Hartwich et al., 2009).

It should be noted that both carbenoxolone and, to a lesser extent, mefloquine, exert actions on neurons in addition to blocking gap junctions (Zhou et al., 2006; Tovar et al., 2009; Connors, 2012). In particular, carbenoxolone has been shown to reduce $\mathrm{GABA}_{\mathrm{A}}$ receptor-mediated signaling (Rouach et al., 2003; Tovar et al., 2009), a mechanism that has been proposed to mediate its seizure blockade effects (Beaumont and Maccaferri, 2011). Therefore, it is possible that the anxiolytic actions of mefloquine and carbenoxolone in the ventral hippocampus and medial prefrontal cortex are the result of engaging non-gap junction mechanisms. However, it should be noted that in our peripheral injection experiments, the control drugs chloroquine and glycyrrhizic acid, which do not block gap junctions (Martin and Handforth, 2006), produced no anxiolytic effects. Of particular note, chloroquine is a 200 -fold more potent inhibitor of $\mathrm{GABA}_{\mathrm{A}}$ responses than mefloquine (Thompson and Lummis, 2008). Conversely, mefloquine has high specificity for blocking cx-36 gap junctions (Cruikshank et al., 2004), and showed the same effects on anxiety-like behavior and theta rhythms as carbenoxolone. Thus, although mefloquine and carbenoxolone have known non- specific effects, our overall pattern of results is consistent with their action on gap junctions in the ventral hippocampus and medial prefrontal cortex.

While our results suggest that neuronal gap junction signaling enables anxious behavior, it is important to note that astrocytic gap junctions have been implicated in anxiety and depressive-like behavior (Prochnow et al., 2012; Sun et al., 2012; Zlomuzica et al., 2012), and astrocytic gap junction abnormalities have been detected in the brains of human suicide completers (Ernst et al., 2011). In these studies, pathological states appear to be associated with diminished astrocytic gap junction signaling. This relationship is the converse of what we observed with neuronal gap junctions where diminished signaling is associated with anxiety relief as opposed to exacerbation. Collectively, these findings suggest a complex role for electrical synapses in the mediation of functional and dysfunctional emotional states. Future experiments examining interactions between glial and neuronal gap junctions will be necessary to expand our understanding of these phenomena.

Anxiety disorders are among the most prevalent of psychiatric illnesses (Kessler et al., 2005) and many of the available pharmacological treatments for anxiety do not produce sufficient relief of symptoms or do so with unwanted side effects (Cloos and Ferreira, 2009; Lorenz et al., 2010). Understanding the neural basis of anxiety regulation seems critical for devising more effective therapies. The extent to which neuronal and glial gap junctions interact and contribute to the emergence of mental illness in humans remains unknown. Using magnetoencephalography in humans, an anxious state has been shown to correlate with theta rhythm in the anterior hippocampus (Cornwell et al., 2012), a region which corresponds to vHIP in rodents (Fanselow and Dong, 2010). Although brain regions in the medial frontal cortex of humans that correspond to the $\mathrm{mPFC}$ in rodents have not been examined for a potential relationship between theta rhythm and anxiety, studies using fMRI have verified increased blood flow in such areas during anxious states (Kalisch et al., 2005; Hasler et al., 2007). Since humans also express cx-36 in the hippocampus and medial frontal cortex (Collignon et al., 2006; Ernst et al., 2011), it seems likely that gap junctions play a similar role in coordinating neuronal activity and regulating anxiety in humans. Together, these find- 
ings raise new possibilities for targeted drug development in the treatment of anxiety disorders.

\section{References}

Adhikari A, Topiwala MA, Gordon JA (2010) Synchronized activity between the ventral hippocampus and the medial prefrontal cortex during anxiety. Neuron 65:257-269. CrossRef Medline

Allen K, Fuchs EC, Jaschonek H, Bannerman DM, Monyer H (2011) Gap junctions between interneurons are required for normal spatial coding in the hippocampus and short-term spatial memory. J Neurosci 31:65426552. CrossRef Medline

Bannerman DM, Grubb M, Deacon RM, Yee BK, Feldon J, Rawlins JN (2003) Ventral hippocampal lesions affect anxiety but not spatial learning. Behav Brain Res 139:197-213. CrossRef Medline

Beaumont M, Maccaferri G (2011) Is connexin36 critical for GABAergic hypersynchronization in the hippocampus? J Physiol 589:1663-1680. CrossRef Medline

Bissiere S, Zelikowsky M, Ponnusamy R, Jacobs NS, Blair HT, Fanselow MS (2011) Electrical synapses control hippocampal contributions to fear learning and memory. Science 331:87-91. CrossRef Medline

Bocian R, Posłuszny A, Kowalczyk T, Gołebiewski H, Konopacki J (2009) The effect of carbenoxolone on hippocampal formation theta rhythm in rats: in vitro and in vivo approaches. Brain Res Bull 78:290-298. CrossRef Medline

Buzsáki G (2002) Theta oscillations in the hippocampus. Neuron 33:325340. CrossRef Medline

Cloos JM, Ferreira V (2009) Current use of benzodiazepines in anxiety disorders. Curr Opin Psychiatry 22:90-95. CrossRef Medline

Collignon F, Wetjen NM, Cohen-Gadol AA, Cascino GD, Parisi J, Meyer FB, Marsh WR, Roche P, Weigand SD (2006) Altered expression of connexin subtypes in mesial temporal lobe epilepsy in humans. J Neurosurg 105:77-87. CrossRef Medline

Connors BW (2012) Tales of a dirty drug: carbenoxolone, gap junctions, and seizures. Epilepsy Curr 12:66-68. CrossRef Medline

Connors BW, Long MA (2004) Electrical synapses in the mammalian brain. Annu Rev Neurosci 27:393-418. CrossRef Medline

Cornwell BR, Arkin N, Overstreet C, Carver FW, Grillon C (2012) Distinct contributions of human hippocampal theta to spatial cognition and anxiety. Hippocampus 22:1848-1859. CrossRef Medline

Crawley JN (1985) Exploratory behavior models of anxiety in mice. Neurosci Biobehav Rev 9:37-44. CrossRef Medline

Cruikshank SJ, Hopperstad M, Younger M, Connors BW, Spray DC, Srinivas M (2004) Potent block of Cx36 and Cx50 gap junction channels by mefloquine. Proc Natl Acad Sci U S A 101:12364-12369. CrossRef Medline

Dragoi G, Carpi D, Recce M, Csicsvari J, Buzsáki G (1999) Interactions between hippocampus and medial septum during sharp wave and theta oscillation in the behaving rat. J Neurosci 19:6191-6199. Medline

Duman CH, Schlesinger L, Russell DS, Duman RS (2008) Voluntary exercise produces antidepressant and anxiolytic behavioral effects in mice. Brain Res 1199:148-158. CrossRef Medline

Ernst C, Nagy C, Kim S, Yang JP, Deng X, Hellstrom IC, Choi KH, Gershenfeld H, Meaney MJ, Turecki G (2011) Dysfunction of astrocyte connexins 30 and 43 in dorsal lateral prefrontal cortex of suicide completers. Biol Psychiatry 70:312-319. CrossRef Medline

Fanselow MS, Dong HW (2010) Are the dorsal and ventral hippocampus functionally distinct structures? Neuron 65:7-19. CrossRef Medline

Franklin KBJ, Paxinos, G (2008) The mouse brain in stereotaxic coordinates, Ed 3. San Diego: Elsevier Academic.

Frisch C, De Souza-Silva MA, Söhl G, Güldenagel M, Willecke K, Huston JP, Dere E (2005) Stimulus complexity dependent memory impairment and changes in motor performance after deletion of the neuronal gap junction protein s36 in mice. Behav Brain Res 157:177-185. CrossRef Medline

Gordon JA, Lacefield CO, Kentros CG, Hen R (2005) State-dependent alterations in hippocampal oscillations in serotonin $1 \mathrm{~A}$ receptor-deficient mice. J Neurosci 25:6509-6519. CrossRef Medline

Hartwich K, Pollak T, Klausberger T (2009) Distinct firing patterns of identified basket and dendrite-targeting interneurons in the prefrontal cortex during hippocampal theta and local spindle oscillations. J Neurosci 29: 9563-9574. CrossRef Medline

Hasler G, Fromm S, Alvarez RP, Luckenbaugh DA, Drevets WC, Grillon C
(2007) Cerebral blood flow in immediate and sustained anxiety. J Neurosci 27:6313-6319. CrossRef Medline

Jones MW, Wilson MA (2005) Phase precession of medial prefrontal cortical activity relative to the hippocampal theta rhythm. Hippocampus 15: 867-873. CrossRef Medline

Kalisch R, Wiech K, Critchley HD, Seymour B, O’Doherty JP, Oakley DA, Allen P, Dolan RJ (2005) Anxiety reduction through detachment: subjective, physiological, and neural effects. J Cogn Neurosci 17:874-883. CrossRef Medline

Kessler RC, Chiu WT, Demler O, Merikangas KR, Walters EE (2005) Prevalence, severity, and comorbidity of twelve-month DSM-IV disorders in the National Comorbidity Survey Replication (NCS-R). Arch Gen Psychiatry 62:617-627. CrossRef Medline

Klausberger T, Magill PJ, Márton LF, Roberts JD, Cobden PM, Buzsáki G, Somogyi P (2003) Brain-state- and cell-type-specific firing of hippocampal interneurons in vivo. Nature 421:844-848. CrossRef Medline

Kozorovitskiy Y, Gross CG, Kopil C, Battaglia L, McBreen M, Stranahan AM, Gould E (2005) Experience induces structural and biochemical changes in the adult primate brain. Proc Natl Acad Sci U S A 102:17478-17482. CrossRef Medline

Lodge DJ, Behrens MM, Grace AA (2009) A loss of parvalbumin-containing interneurons is associated with diminished oscillatory activity in an animal model of schizophrenia. J Neurosci 29:2344-2354. CrossRef Medline

Lorenz RA, Jackson CW, Saitz M (2010) Adjunctive use of atypical antipsychotics for treatment-resistant generalized anxiety disorder. Pharmacotherapy 30:942-951. CrossRef Medline

Martin FC, Handforth A (2006) Carbenoxolone and mefloquine suppress tremor in the harmaline mouse model of essential tremor. Mov Disord 21:1641-1649. CrossRef Medline

McEown K, Treit D (2010) Inactivation of the dorsal or ventral hippocampus with muscimol differentially affects fear and memory. Brain Res 1353: 145-151. CrossRef Medline

McEown K, Treit D (2011) Mineralocorticoid receptors in the medial prefrontal cortex and hippocampus mediate rats' unconditioned fear behaviour. Horm Behav 60:581-588. CrossRef Medline

McEown K, Treit D (2013) A2 GABAA receptor sub-units in the ventral hippocampus and $\alpha 5$ GABAA receptor sub-units in the dorsal hippocampus mediate anxiety and fear memory. Neuroscience 252:169-177. CrossRef Medline

McNaughton N, Kocsis B, Hajos M (2007) Elicited hippocampal theta rhythm: a screen for anxiolytic and procognitive drugs through changes in hippocampal function? Behav Pharmacol 18:329-346. CrossRef Medline

O'Keefe J (2007) Hippocampal neurophysiology in the behaving animal. In: The hippocampus book (Andersen P, Morris R, Amaral D, Bliss T, O'Keefe J, eds), pp 475-548. Oxford: Oxford UP.

Prochnow N, Abdulazim A, Kurtenbach S, Wildförster V, Dvoriantchikova G, Hanske J, Petrasch-Parwez E, Shestopalov VI, Dermietzel R, ManahanVaughan D, Zoidl G (2012) Pannexin1 stabilizes synaptic plasticity and is needed for learning. PLoS One 7:e51767. CrossRef Medline

Rouach N, Segal M, Koulakoff A, Giaume C, Avignone E (2003) Carbenoxolone blockade of neuronal network activity in culture is not mediated by an action on gap junctions. J Physiol 553:729-745. CrossRef Medline

Salam JN, Fox JH, Detroy EM, Guignon MH, Wohl DF, Falls WA (2009) Voluntary exercise in C57 mice is anxiolytic across several measures of anxiety. Behav Brain Res 197:31-40. CrossRef Medline

Schoenfeld TJ, Rada P, Pieruzzini PR, Hsueh B, Gould E (2013) Physical exercise prevents stress-induced activation of granule neurons and enhances local inhibitory mechanisms in the dentate gyrus. J Neurosci 33: 7770-7777. CrossRef Medline

Shah AA, Sjovold T, Treit D (2004) Inactivation of the medial prefrontal cortex with the GABAA receptor agonist muscimol increases open-arm activity in the elevated plus-maze and attenuates shock-probe burying in rats. Brain Res 1028:112-115. CrossRef Medline

Söhl G, Maxeiner S, Willecke K (2005) Expression and functions of neuronal gap junctions. Nat Rev Neurosci 6:191-200. CrossRef Medline

Sun JD, Liu Y, Yuan YH, Li J, Chen NH (2012) Gap junction dysfunction in the prefrontal cortex induces depressive-like behaviors in rats. Neuropsychopharmacology 37:1305-1320. CrossRef Medline

Thompson AJ, Lummis SC (2008) Antimalarial drugs inhibit human 5-HT(3) and GABA(A) but not GABA(C) receptors. Br J Pharmacol 153: 1686-1696. CrossRef Medline 
Tovar KR, Maher BJ, Westbrook GL (2009) Direct actions of carbenoxolone on synaptic transmission and neuronal membrane properties. J Neurophysiol 102:974-978. CrossRef Medline

Trejo JL, Llorens-Martin MV, Torres-Alemán I (2008) The effects of exercise on spatial learning and anxiety are mediated by an IGF-1 dependent mechanism related to hippocampal neurogenesis. Mol Cell Neurosci 37: 402-411. CrossRef Medline

Walf AA, Frye CA (2007) The use of the elevated plus maze as an assay of anxiety-related behavior in rodents. Nat Protoc 2:322-328. CrossRef Medline

Wells CE, Amos DP, Jeewajee A, Douchamps V, Rodgers J, O'Keefe J, Burgess N, Lever C (2013) Novelty and anxiolytic drugs dissociate two components of hippocampal theta in behaving rats. J Neurosci 33:8650-8667. CrossRef Medline

Yeung M, Treit D, Dickson CT (2012) A critical test of the hippocampal theta model of anxiolytic drug action. Neuropharmacology 62:155-160. CrossRef Medline

Yeung M, Dickson CT, Treit D (2013a) Intrahippocampal infusion of the Ih blocker ZD7288 slows evoked theta rhythm and produces anxiolytic-like effects in the elevated plus maze. Hippocampus 23:278-286. CrossRef Medline

Yeung M, Lu L, Hughes AM, Treit D, Dickson CT (2013b) FG7142, yohimbine, and $\beta C C E$ produce anxiogenic-like effects in the elevated plus-maze but do not affect brainstem activated hippocampal theta. Neuropharmacology 75:47-52. CrossRef Medline

Zhou C, Xiao C, McArdle JJ, Ye JH (2006) Mefloquine enhances nigral gamma-aminobutyric acid release via inhibition of cholinesterase. J Pharmacol Exp Ther 317:1155-1160. CrossRef Medline

Zhu XO, McNaughton N (1994) Effects of long-term administration of antidepressants on septal driving of hippocampal RSA. Int J Neurosci 79:9198. Medline

Zlomuzica A, Tress O, Binder S, Rovira C, Willecke K, Dere E (2012) Changes in object recognition and anxiety-like behaviour in mice expressing a $\mathrm{Cx} 47$ mutation that causes Pelizaeus-Merzbacher-like disease. Dev Neurosci 34:277-287. CrossRef Medline 